September 2016

\title{
Venous thromboembolism following hematopoietic stem cell transplantation-a systematic review and meta-analysis
}

Mohammad Faizan Zahid

Aga Khan University

M Hassan Murad

Mark R. Litzow

Hogan

William J. Hogan

Mrinal S. Patnaik

See next page for additional authors

Follow this and additional works at: https://ecommons.aku.edu/pakistan_fhs_mc_mc

Part of the Medical Sciences Commons

\section{Recommended Citation}

Zahid, M. F., Murad, M. H., Litzow, M. R., Hogan, W. J., Patnaik, M. S., Khorana, A., Spyropoulos, A. C., Hashmi, S. K. (2016). Venous thromboembolism following hematopoietic stem cell transplantation-a systematic review and meta-analysis. Annals of Hematology, 95(9), 1457-1464.

Available at: https://ecommons.aku.edu/pakistan_fhs_mc_mc/77 
Authors

Mohammad Faizan Zahid, M Hassan Murad, Mark R. Litzow, William J. Hogan, Mrinal S. Patnaik, Alok Khorana, Alex C. Spyropoulos, and Shahrukh K. Hashmi 


\title{
Venous thromboembolism following hematopoietic stem cell transplantation-a systematic review and meta-analysis
}

\author{
Mohammad Faizan Zahid ${ }^{1}$ - M. Hassan Murad ${ }^{2,3,4} \cdot$ Mark R. Litzow $^{5}$ • \\ William J. Hogan $^{5}$ - Mrinal S. Patnaik ${ }^{5}$ Alok Khorana ${ }^{6}$ - Alex C. Spyropoulos ${ }^{7}$. \\ Shahrukh K. Hashmi ${ }^{5}$
}

Received: 6 March 2016 / Accepted: 11 April 2016/Published online: 22 April 2016

(C) Springer-Verlag Berlin Heidelberg 2016

\begin{abstract}
Venous thromboembolism (VTE) is a common complication of hematopoietic stem cell transplantation (HSCT). Graft-versus-host disease (GVHD) is another complication of HSCT that may modify the risk of VTE. Our objective was to explore the incidence of VTE (deep venous thrombosis and pulmonary embolism) following HSCT and to evaluate its association with GVHD. A comprehensive search of Medline In-Process \& Other Non-Indexed Citations, MEDLINE, EMBASE, Cochrane Central Register of Controlled Trials, and Scopus was conducted to search for both retrospective and prospective HSCT studies which had reported VTE. Random-effects meta-analysis was used to pool incidence rates. We included 17 studies reporting on allogeneic- and 10 on autologous-HSCT; enrolling 6693 patients; of which 5 were randomized. The overall incidence of
\end{abstract}

Electronic supplementary material The online version of this article (doi:10.1007/s00277-016-2673-3) contains supplementary material, which is available to authorized users.

Shahrukh K. Hashmi

Hashmi.Shahrukh@mayo.edu

1 Medical Graduate, Aga Khan University, Karachi, Pakistan

2 Evidence-Based Practice Program, Mayo Clinic, Rochester, MN, USA

3 Center for the Science of Healthcare Delivery, Mayo Clinic, Rochester, MN, USA

4 Division of Preventive, Occupational, and Aerospace Medicine, Mayo Clinic, Rochester, MN, USA

5 Mayo Clinic Transplant Center, Blood and Marrow Transplant Program, Mayo Clinic, Rochester, MN, USA

6 Taussig Cancer Institute, Department of Hematology and Oncology, Cleveland Clinic, Cleveland, OH, USA

7 Hofstra-North Shore LIJ School of Medicine, Manhasset, NY, USA
VTE after HSCT was $5 \%(4-7 \%)$. Incidence in allogeneicHSCT was $4 \%(2-6 \%)$ and in autologous-HSCT was $4 \%(1-$ $15 \%)$. Eleven and nine studies reported data on acute and chronic GVHD, respectively. The incidence of VTE in chronic GVHD was $35 \%(20-54 \%)$, whereas in acute GVHD it was $47 \%(32-62 \%)$. Based on the results of this meta-analysis, VTE is a fairly common complication after HSCT, emphasizing the importance of assimilating guidelines for both treatment and prophylaxis in this patient population.

Keywords Venous thromboembolism · Deep venous thrombosis $\cdot$ Pulmonary embolism $\cdot$ Bone marrow transplantation $\cdot$ Hematopoietic stem cell transplantation . Complication

\section{Introduction}

Hematopoietic stem cell transplantation (HSCT) is the standard of care in a variety of benign and malignant hematologic disorders and is being employed at an increasing frequency in the last two decades [1].

Recent studies have recognized that thromboembolic complications, such as venous thromboembolism (VTE), are a serious cause of morbidity and mortality in HSCT patients [2-5]. Recipients of HSCT are prone to develop VTE due to several risk factors. These include underlying cancer, indwelling central venous catheters, hospital admission leading to prolonged periods of immobility, cytotoxic chemotherapy or radiation therapy as preparative regimens, infections, and graft-versus-host disease (GVHD) [2, 3].

Hepatic sinusoidal obstruction syndrome (SOS) and thrombotic microangiopathy (TMA) are well-known thrombotic complications following HSCT [6, 7]. SOS is usually related to high-dose cytotoxic chemotherapy, as is used in 
myeloablative conditioning regimens [8], while TMA can be associated with the use of calcineurin inhibitors, sirolimus, and rarely GVHD [9, 10]. However, the incidence and risk factors for VTE following HSCT are not well defined. HSCT patients are also at an increased risk of bleeding following transplant $[1,2]$, which has been associated with a shorter survival in such patients [11]. Consequently, clinicians face a difficult choice regarding VTE prophylaxis in HSCT patients and lack sufficient information to make informed decisions. There is little information regarding appropriate therapeutic and prophylactic approaches to VTE in this complex patient population. The incidence of VTE in HSCT has been reported with variable frequencies, ranging from $0.5 \%$ to as high as $23.5 \%[12,13]$.

Given the increasing recognition of the endothelial form of GVHD resulting in an increase in cardiovascular complications, we hypothesized that VTE incidence would be heightened in patients suffering from GVHD [14].

Thus, we performed a systematic review and meta-analysis to assess the overall incidence of VTE following HSCT, including deep venous thrombosis (DVT) and pulmonary embolism (PE). We also assessed the likelihood of VTE following allogeneic-HSCT and autologous-HSCT, separately.

\section{Materials and methods}

This systematic review and meta-analysis is reported following criteria set by the Preferred Reporting Items for Systematic reviews and Meta-Analyses (PRISMA) statement (http:// www.prisma-statement.org) [15].

\section{Eligibility criteria}

Types of studies We searched literature databases for clinical trials as well as prospective and retrospective observational studies with patients receiving allogeneic- and/or autologous-HSCT. Studies reporting the outcome and complications in these patients (venous thrombosis alone or in addition to other complications of HSCT) were included.

Types of participants We included all patients receiving either allogeneic- or autologous-HSCT for treatment. There were no restrictions in regards to age, ethnicity, gender, or underlying disease for which HSCT was being performed.

Types of outcome measures The primary outcome was the development of thrombosis in the venous system after the infusion of hematopoietic stem cells following pre-transplant conditioning chemotherapy. This included upper and lower extremity DVT, PE, thrombosis in veins related to internal organs (e.g., hepatic vein, internal jugular vein, etc.), and thrombosis associated with indwelling catheters used during the transplantation process.

Exclusion criteria The exclusion criteria are as follows: (1) case reports, case series and studies with patient population of $<5$ (to avoid statistical skewing of the results); (2) studies involving patients that do not represent typical HSCT patients (e.g., involving the use of erythropoiesis-stimulating agents, immunotherapy, or other interventions that are not typically used simultaneously with HSCT, immunotherapy with subcutaneous IL-2 after transplant, multiple myeloma patients who had relapsed disease after getting allogeneic-HSCT and were getting lenalidomide as salvage treatment, multiple myeloma patients getting thalidomide immediately after getting autotransplant, etc.); (3) review articles and studies in which patients who developed VTE after HSCT were not quantifiable; (4) studies describing thrombotic complications other than VTE, e.g., SOS or arterial thrombosis; (5) autopsy studies reporting VTE in HSCT patients (to maintain uniformity); (6) studies reporting only catheter-related thrombosis; and (7) studies describing VTE in patients prior to HSCT or in non-HSCT patients.

\section{Information sources and search strategy}

A comprehensive search of several databases from each database's earliest inception to June 2014, in any language, was conducted. The databases included Medline In-Process \& Other Non-Indexed Citations, MEDLINE, EMBASE, Cochrane Central Register of Controlled Trials, and Scopus. The search strategy was designed and conducted by an experienced librarian with input from the study's principal investigator. Controlled vocabulary supplemented with keywords was used to search for studies of VTE in bone marrow transplantation. The actual strategy is available in Appendix.

\section{Study selection and data collection}

Two investigators (SKH and MFZ) independently screened all studies by reviewing titles and abstracts. Potentially relevant studies were retrieved as full text articles. All full text articles were screened again in duplicate following the same inclusion criteria. In case of any disagreement in regards to inclusion of a study, this was discussed with a third investigator (MSP). All studies were critically appraised in regards to relevance and validity for inclusion in this systematic review or for further exclusion. Data were collected for the variables described in data items below and recorded in an excel sheet.

The following data were extracted from each study: author, year of publication, total study population, indication for HSCT, type of HSCT (allogeneic vs. autologous), total incidence of VTE, and type of VTE (PE, DVT, catheter-related thrombosis, etc). Our primary outcome was the occurrence of 
first VTE. We defined VTE as thrombosis involving the deep veins of any extremity detected by any standard radiologic means.

\section{Study quality appraisal (risk of bias)}

The Cochrane Collaboration's tool for assessing risk of bias was used for quality appraisal of randomized studies [16] (Table 1). We used the Newcastle-Ottawa Scale for assessing the quality of non-randomized studies [21] (Table 2).

\section{Statistical analysis}

Statistical analysis was performed using Comprehensive Meta-Analysis Version 2.0 (Englewood, NJ). We used the random-effects model to pool outcomes across studies due to anticipated heterogeneity. Outcome measure was evaluated as cumulative incidence (i.e., event rate). Subgroup analyses were undertaken based on (a) allogeneic vs. autologous transplants, (b) presence of GVHD, and (c) type of GVHD, i.e., acute vs. chronic.

\section{Results}

Electronic search yielded 755 articles (Fig. 1) out of which only 146 articles were relevant to the study question. Many studies reported patients that developed VTE after HSCT, but the incidence could not be quantified so they were excluded. Thrombotic complications other than VTE, e.g., SOS or arterial thrombosis $(n=13)$, were excluded. However, if they had also reported VTE incidences, then the VTE numbers were included in the analysis. Studies reporting VTE in HSCT patients prior to stem cell infusion or in non-HSCT patients $(n=18)$ were also excluded. Some studies $(n=4)$ had reported postmortem finding of VTE and they were excluded. Only 23 studies fulfilled the strict inclusion criteria and were included in the statistical analysis. The randomized trials and the observational studies had moderate risk of bias, overall.

Twelve studies in allogeneic-HSCT yielded an incidence rate of $4 \%$ (95\% CI 2-6\%) with significant heterogeneity $\left(I_{2}=80\right)$. Six studies in autologous-HSCT yielded a similar incident rate of $4 \%$ (95\% CI 1-15\%) with significant heterogeneity $\left(I_{2}=89\right)$. Five studies with patients undergoing both autologous- and allogeneic-HSCT yielded an incident rate of $6 \%(4-9 \%)$ with significant heterogeneity $\left(I_{2}=93\right)$. There was no significant difference in the incidence of VTE between allogeneic- and autologous-HSCT $(p=0.94)$. Overall VTE incidence from 23 studies was $5 \%(4-7 \%)$.

When we analyzed the GVHD data with respect to VTE incidence, 11 studies reported data on acute GVHD in which the incidence of VTE was found to be very high at $47 \%(95 \%$ CI 32-62 \%) with significant heterogeneity $\left(I_{2}=98\right)$. The incidence of VTE in chronic GVHD from nine studies was also found to be very high at $35 \%$ (95\% CI 20-54 \%) indicating a possibly strong association with GVHD.

\section{Discussion}

We conducted a systematic review and meta-analysis of studies evaluating VTE after HSCT. We found that VTE is fairly common with an overall incidence of $5 \%$. In patients with GVHD, the risk was much higher. The certainty in these estimates is limited due to the presence of heterogeneity that remained unexplained and likely reflects differences in outcome surveillance and ascertainment as well as heterogeneity in the population's other risk factors for VTE.

Clinically apparent VTE occurs in up to $10 \%$ of patients with active cancer [33], and many algorithms exist which can predict the risk of cancer thrombosis among which the Khorana model is regarded as the gold standard [34]. No such model exists for HSCT patients due to the absence of data on the risks and outcomes of VTE in this population. Theoretically, HSCT survivors who do not have any relapses of cancer should not have an elevated risk of VTE unless other known risk factors are present or new factors are acquired. A well-known non-relapse risk factor of VTE in HSCT patients is the presence of central venous catheters which are inserted in majority of the patients undergoing HSCT [2, 3, 32]. Some studies have indicated HSCT-associated VTE incidences of $0.5 \%$ [13], whereas other studies have indicated an incidence as high as $23.5 \%$ [12] post-HSCT. To delineate the totality of evidence of VTE risks and outcomes in HSCT population, we undertook this meta-analysis.

Our meta-analysis of both observational studies and randomized clinical trials showed that the overall risk of VTE post-HSCT was similar to that described by Gerber et al. [2]. We found no significant difference between allogeneic- and autologous-HSCT for VTE occurrence. However, when we undertook the analysis of GVHD with VTE, a significantly high risk of VTE was observed both in acute and chronic GVHD of 47 and $35 \%$, respectively.

Besides being the first meta-analysis on the risk of VTE in HSCT patients, this analysis separates out the risk of provoked (line associated) vs. unprovoked VTE. We did a comprehensive qualitative assessment of the prospective randomized studies included in our meta-analysis using Cochrane Collaboration's tool for assessing risk of bias. Our strict selection criteria excluded VTE post-HSCT in the patients with pre-existing hypercoagulable states. We did the analysis based on both chronic and acute GVHD for VTE incidence to ascertain a possible association of GVHD with VTE.

In 1856, Virchow proposed a triad of causes for venous thrombosis, postulating that stasis, changes in the vessel wall, or changes in the blood could lead to thrombosis. GVHD can 


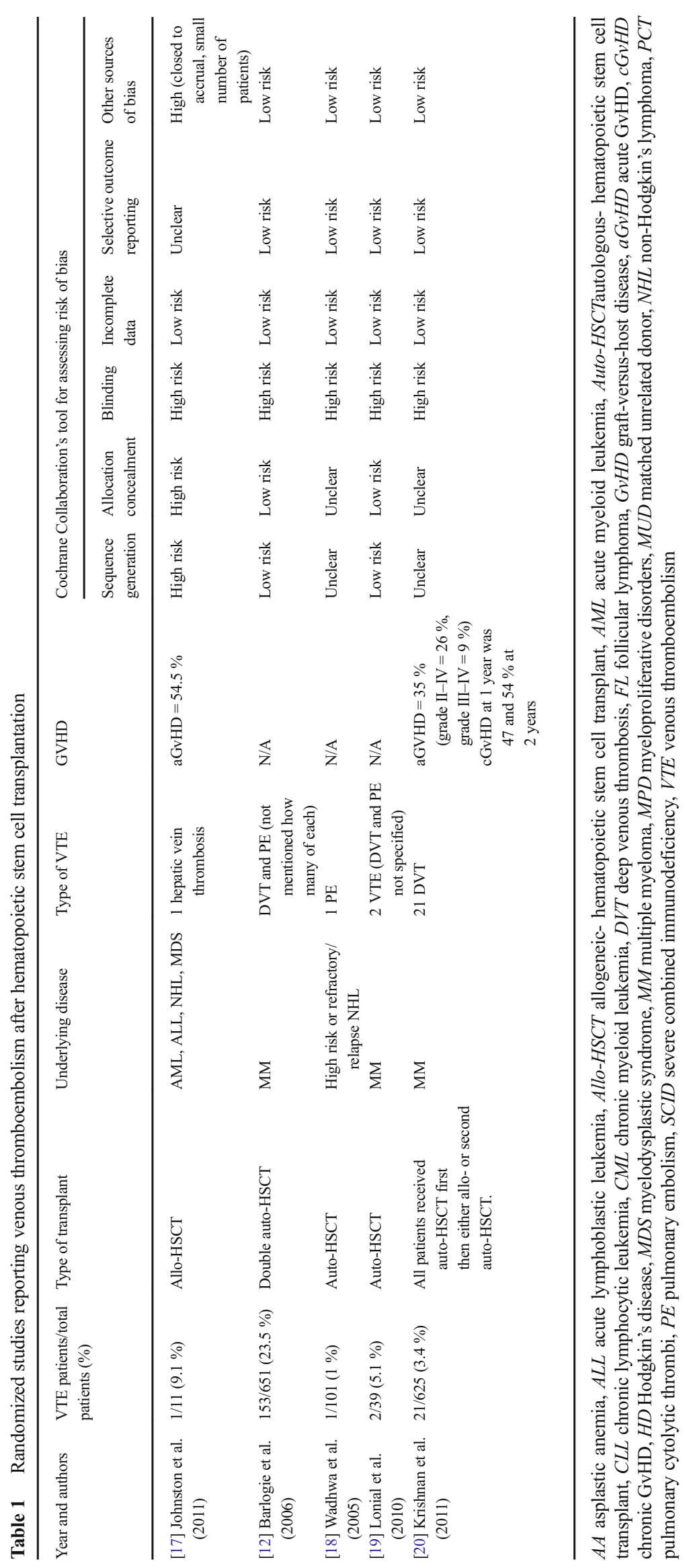




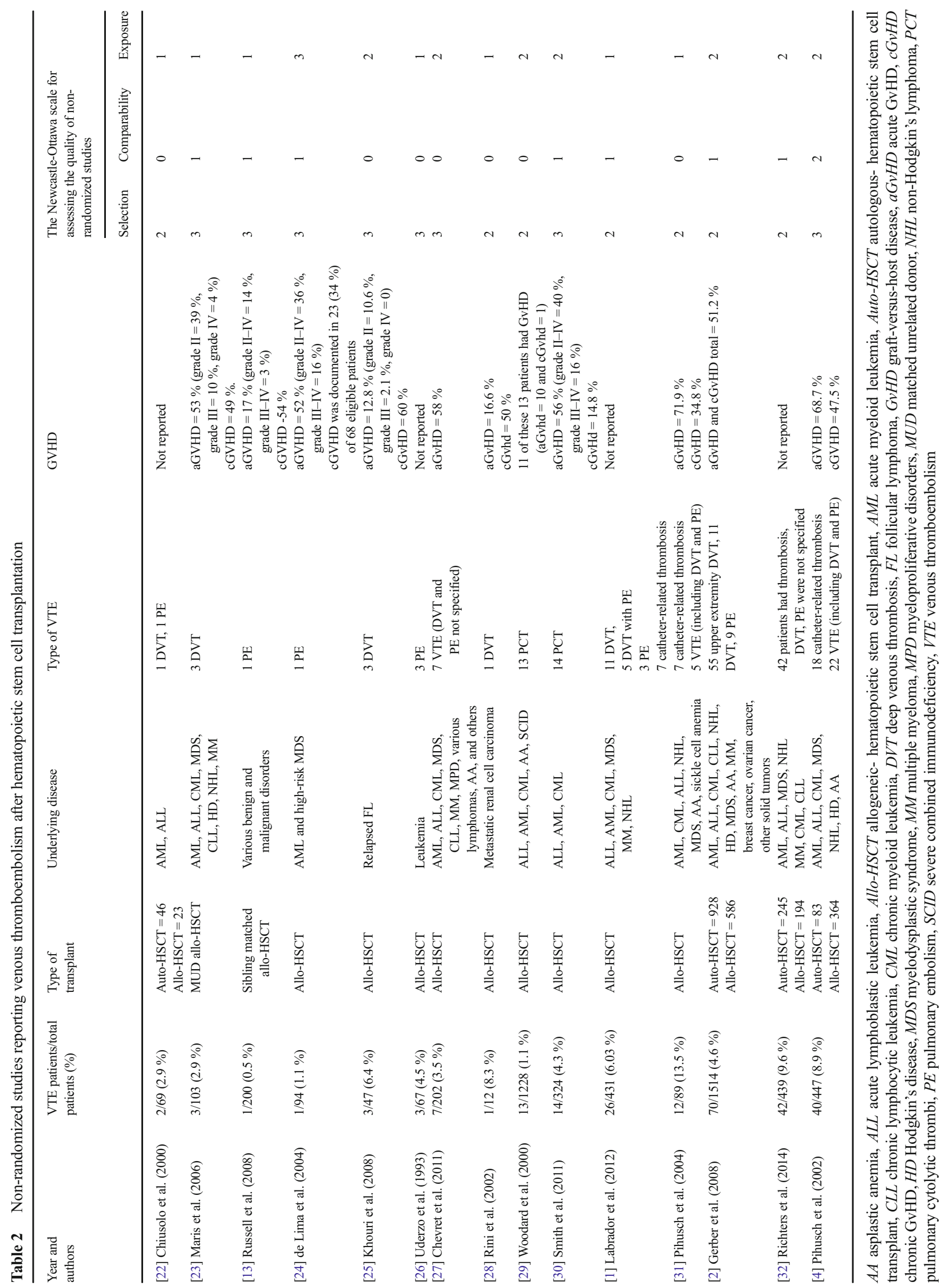


Fig. 1 Search and inclusion of selected studies

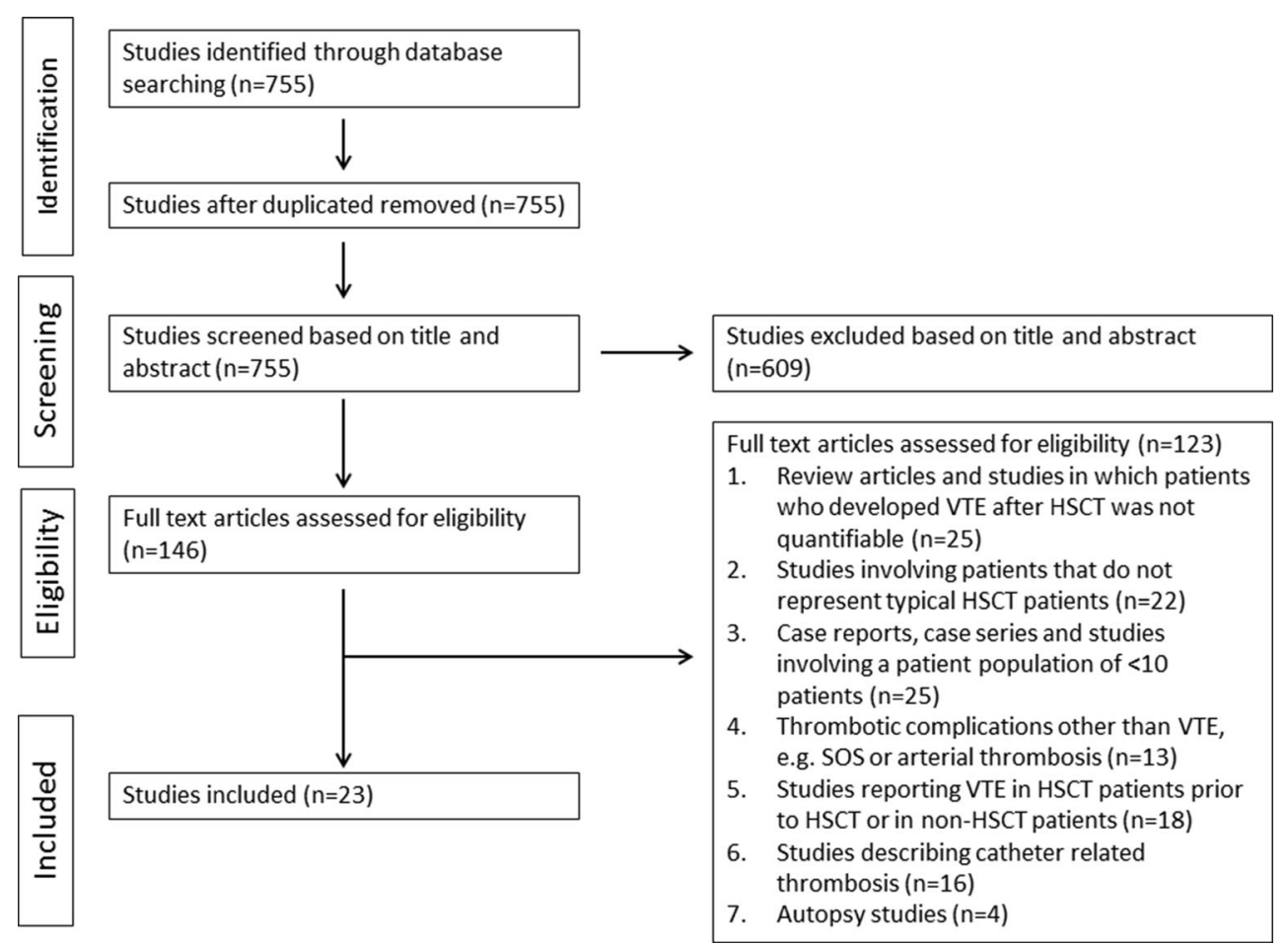

cause significant endothelial injury which can result in a multitude of inflammatory cascades resulting in cytokine storm especially in the setting of acute GVHD $[35,36]$. The role of donor T cells post-allogeneic-HSCT adhering to endothelium in the vasculature as the first potential extensive area of contact with new host antigens is well established [37, 38]. For chronic GVHD which exhibits a unique pathogenesis distinct from acute GVHD [39], current evidence indicates that, in addition to damage to targeted epithelia, changes to the microvascular endothelium play a role in the pathogenesis of chronic GVHD [40-42]. It is well known that long-term survivors after allogeneic-HSCT are at a high risk for premature arterial vascular disease [43-45]. The common endothelial syndromes that HSCT patients suffer from include TMA, SOS, engraftment syndrome, and capillary leak syndrome $[6,7,46-48]$. These early transplant-related endothelial damage syndromes result mainly due to direct cellular toxicity, a potent procoagulant condition, and heightened inflammatory responses manifested by cytokine storms post-HSCT. Thus, adequate mechanisms are well documented that provide a rationale for the biologic plausibility of a high thrombotic state in GVHD.

Since the incidence of VTE was reported as an adverse event in most of the studies and was not the primary outcome for most of the clinical trials, a definite causal link between GVHD and VTE cannot be established. Many other residual confounding factors may be present as the studies did not report all potential risk factors for GVHD.

Although we removed the studies (and/or patients in individualized studies) with catheter-related GVHD, it is possible that some studies did not report presence or absence of central catheters since many patients at the time of HSCT and postHSCT for few weeks or months still have catheters present, thus potentially confounding the association of VTE with acute GVHD. In chronic GVHD, although not reported in most studies, it is unlikely that majority of patients had central catheters, unless required for a treatment modality such as photopheresis. A VTE incidence of $35 \%$ in chronic GVHD is alarming and suggests the need for further definitive studies to prove (or disprove) a causal link of GVHD with VTE. However, one must consider the possibility that these results may overestimate the incidence and link of VTE with GVHD. The details of GVHD were not available from each study; however, in all studies where the grades of GVHD were mentioned, they were compared. Incidental findings of VTE may also overestimate its incidence in HSCT patients, who usually undergo various investigations and extensive follow-up tests for various indications. The same incidence may not be true in patients with hematologic disorders being treated with nontransplant modalities. Another limitation in the present metaanalysis is that patient level (individual level) data was not available from each study. In addition, the included studies were inconsistent in reporting symptomatic VTE against asymptomatic VTE. While symptomatic VTE is a clear indication for therapeutic interventions, guidelines for the approach/treatment of asymptomatic VTE are not defined and open for discussion. Since incidental/asymptomatic VTE findings are common in HSCT patients considering the high rate of diagnostic procedures performed in this patient population, it is imperative to develop such protocols to guide 
clinical practice. Exploring the incidence of symptomatic against asymptomatic VTE also represents a potential topic of future research interest.

It is evident from this meta-analysis that patients undergoing HSCT are at an elevated risk of both PE and DVT. Currently, the practice of DVT prophylaxis varies significantly between institutions as some transplant centers routinely provide anticoagulants post-HSCT for the prevention of SOS. Additionally, in autologous-HSCTs, a special consideration may be post-HSCT immuno-modulatory drug therapy which may be a risk factor for VTE post-HSCT. Lastly, the potential association of immobility due to severe chronic GVHD and VTE needs to be further evaluated in long-term studies.. Definitive prospective trials are also needed to confirm the absolute and relative risks of VTE in HSCT patients and to prove the causal relationship between GVHD and VTE.

Acknowledgments We acknowledge Larry Prokop MLS for conducting electronic search.

\section{Compliance with ethical standards}

Conflict of interest None

\section{References}

1. Labrador J, Lopez-Anglada L, Perez-Lopez E, Lozano FS, LopezCorral L, Sanchez-Guijo FM et al (2013) Analysis of incidence, risk factors and clinical outcome of thromboembolic and bleeding events in 431 allogeneic hematopoietic stem cell transplantation recipients. Haematologica 98(3):437-443

2. Gerber DE, Segal JB, Levy MY, Kane J, Jones RJ, Streiff MB (2008) The incidence of and risk factors for venous thromboembolism (VTE) and bleeding among 1514 patients undergoing hematopoietic stem cell transplantation: implications for VTE prevention. Blood 112(3):504-510

3. Gonsalves A, Carrier M, Wells PS, McDiarmid SA, Huebsch LB, Allan DS (2008) Incidence of symptomatic venous thromboembolism following hematopoietic stem cell transplantation. J Thromb Haemost 6(9):1468-1473

4. Pihusch R, Salat C, Schmidt E, Göhring P, Pihusch M, Hiller E et al (2002) Hemostatic complications in bone marrow transplantation: a retrospective analysis of 447 patients. Transplantation 74(9):13031309

5. Tsakiris DA, Tichelli A (2009) Thrombotic complications after haematopoietic stem cell transplantation: early and late effects. Best Pract Res Clin Haematol 22(1):137-145

6. Carreras E (ed) (2012) Early complications after HSCT. The EBMT handbook on haematopoietic stem cell transplantation Forum Service, Genova

7. Copelan EA (2006) Hematopoietic stem-cell transplantation. N Engl J Med 354(17):1813-1826

8. Helmy A (2006) Review article: updates in the pathogenesis and therapy of hepatic sinusoidal obstruction syndrome. Aliment Pharmacol Ther 23(1):11-25

9. Cutler C, Henry NL, Magee C, Li S, Kim HT, Alyea E et al (2005) Sirolimus and thrombotic microangiopathy after allogeneic hematopoietic stem cell transplantation. Biol Blood Marrow Transplant 11(7):551-557

10. Kojouri K, George JN (2007) Thrombotic microangiopathy following allogeneic hematopoietic stem cell transplantation. Curr Opin Oncol 19(2):148-154

11. Pihusch M (ed) (2004) Bleeding complications after hematopoietic stem cell transplantation. Semin Hematol 41(Suppl 1):93-100

12. Barlogie B, Tricot G, Anaissie E, Shaughnessy J, Rasmussen E, van Rhee F et al (2006) Thalidomide and hematopoietic-cell transplantation for multiple myeloma. N Engl J Med 354(10):1021-1030

13. Russell JA, Duan Q, Chaudhry MA, Savoie ML, Balogh A, Turner AR et al (2008) Transplantation from matched siblings using oncedaily intravenous busulfan/fludarabine with thymoglobulin: a myeloablative regimen with low nonrelapse mortality in all but older patients with high-risk disease. Biol Blood Marrow Transplant 14(8):888-895

14. Tichelli A, Gratwohl A (2008) Vascular endothelium as 'novel' target of graft-versus-host disease. Best Pract Res Clin Haematol 21(2):139-148

15. Moher D, Liberati A, Tetzlaff J, Altman DG (2009) Preferred reporting items for systematic reviews and meta-analyses: the PRISMA statement. Ann Intern Med 151(4):264-269

16. Higgins JPT, Altman DG, Gøtzsche PC, Jüni P, Moher D, Oxman $\mathrm{AD}$ et al (2011) The Cochrane Collaboration's tool for assessing risk of bias in randomised trials. BMJ 343:d5928

17. Johnston L, Florek M, Armstrong R, McCune JS, Arai S, Brown J et al (2012) Sirolimus and mycophenolate mofetil as GVHD prophylaxis in myeloablative, matched-related donor hematopoietic cell transplantation. Bone Marrow Transplant 47(4):581-588

18. Wadhwa PD, Fu P, Koc ON, Cooper BW, Fox RM, Creger RJ et al (2005) High-dose carmustine, etoposide, and cisplatin for autologous stem cell transplantation with or without involved-field radiation for relapsed/refractory lymphoma: an effective regimen with low morbidity and mortality. Biol Blood Marrow Transplant 11(1): $13-22$

19. Lonial S, Kaufman J, Tighiouart M, Nooka A, Langston AA, Heffner LT et al (2010) A phase I/II trial combining high-dose melphalan and autologous transplant with bortezomib for multiple myeloma: a dose-and schedule-finding study. Clin Cancer Res 16(20):5079-5086

20. Krishnan A, Pasquini MC, Logan B, Stadtmauer EA, Vesole DH, Alyea E et al (2011) Autologous haemopoietic stem-cell transplantation followed by allogeneic or autologous haemopoietic stem-cell transplantation in patients with multiple myeloma (BMT CTN 0102): a phase 3 biological assignment trial. Lancet Oncol 12(13): 1195-1203

21. Wells GA, Shea B, O'connell D, Peterson JEA, Welch V, Losos M et al (2000) The Newcastle-Ottawa Scale (NOS) for assessing the quality of nonrandomised studies in meta-analyses

22. Chiusolo P, Sica S, De Stefano V, Casorelli I, Laurenti L, Leone G (2000) Incidence of Factor V Leiden and prothrombin G20210A in patients submitted to stem cell transplantation. Haematologica 85(6):670-671

23. Maris MB, Sandmaier BM, Storer BE, Maloney DG, Shizuru JA, Agura E et al (2006) Unrelated donor granulocyte colonystimulating factor-mobilized peripheral blood mononuclear cell transplantation after nonmyeloablative conditioning: the effect of postgrafting mycophenolate mofetil dosing. Biol Blood Marrow Transplant 12(4):454-465

24. de Lima M, Anagnostopoulos A, Munsell M, Shahjahan M, Ueno $\mathrm{N}$, Ippoliti C et al (2004) Nonablative versus reduced-intensity conditioning regimens in the treatment of acute myeloid leukemia and high-risk myelodysplastic syndrome: dose is relevant for long-term disease control after allogeneic hematopoietic stem cell transplantation. Blood 104(3):865-872 
25. Khouri IF, McLaughlin P, Saliba RM, Hosing C, Korbling M, Lee MS et al (2008) Eight-year experience with allogeneic stem cell transplantation for relapsed follicular lymphoma after nonmyeloablative conditioning with fludarabine, cyclophosphamide, and rituximab. Blood 111(12):5530-5536

26. Uderzo C, Marraro G, Riva A, Bonanomi E, Vaj PL, Marchi PF et al (1993) Pulmonary thromboembolism in leukaemic children undergoing bone marrow transplantation. Bone Marrow Transplant 11(3):201-203

27. Chevret S, Chagnon K, Petropoulou A, Robin M, Desseaux K, de Latour RP et al (2011) Prospective evaluation of the incidence, risk factors and clinical outcome of late onset non infectious pulmonary complications after allogeneic hematopoietic stem cell transplantation. Am J Respir Crit Care Med 183:A4667

28. Rini BI, Zimmerman T, Stadler WM, Gajewski TF, Vogelzang NJ (2002) Allogeneic stem-cell transplantation of renal cell cancer after nonmyeloablative chemotherapy: feasibility, engraftment, and clinical results. J Clin Oncol 20(8):2017-2024

29. Woodard JP, Gulbahce E, Shreve M, Steiner M, Peters C, Hite S et al (2000) Pulmonary cytolytic thrombi: a newly recognized complication of stem cell transplantation. Bone Marrow Transplant 25(3):293-300

30. Smith AR, Gulbahce E, Burke MJ, Cao Q, MacMillan ML, Tolar J et al (2011) Lower leukemia relapse in pediatric patients with pulmonary cytolytic thrombi following allogeneic transplant. Bone Marrow Transplant 46(3):368-371

31. Pihusch M, Lohse P, Reitberger J, Hiller E, Andreesen R, Kolb H-J et al (2004) Impact of thrombophilic gene mutations and graftversus-host disease on thromboembolic complications after allogeneic hematopoietic stem-cell transplantation. Transplantation 78(6): 911-918

32. Richters A, Van Vliet M, Peer PGM, Verweij PE, Laros-van Gorkom BAP, Blijlevens NMA et al (2014) Incidence of and risk factors for persistent gram-positive bacteraemia and catheterrelated thrombosis in haematopoietic stem cell transplantation. Bone Marrow Transplant 49(2):264-269

33. Timp JF, Braekkan SK, Versteeg HH, Cannegieter SC (2013) Epidemiology of cancer-associated venous thrombosis. Blood 122(10):1712-1723

34. Khorana AA, Kuderer NM, Culakova E, Lyman GH, Francis CW (2008) Development and validation of a predictive model for chemotherapy-associated thrombosis. Blood 111(10):4902-4907

35. Fujimori Y, Takatsuka H, Takemoto Y, Hara H, Okamura H, Nakanishi K et al (2000) Elevated interleukin (IL)-18 levels during acute graft-versus-host disease after allogeneic bone marrow transplantation. Br J Haematol 109(3):652-657

36. Jadus MR, Wepsic HT (1992) The role of cytokines in graft-versushost reactions and disease. Bone Marrow Transplant 10(1):1-14
37. Behar E, Chao NJ, Hiraki DD, Krishnaswamy S, Brown BW, Zehnder JL et al (1996) Polymorphism of adhesion molecule CD31 and its role in acute graft-versus-host disease. N Engl J Med 334(5):286-291

38. Maruya E, Saji H, Seki S, Fujii Y, Kato K, Kai S et al (1998) Evidence that CD31, CD49b, and CD62L are immunodominant minor histocompatibility antigens in HLA identical sibling bone marrow transplants. Blood 92(6):2169-2176

39. Shulman HM, Cardona DM, Greenson JK, Hingorani S, Horn T, Huber E et al (2015) NIH Consensus Development Project on Criteria for Clinical Trials in Chronic Graft-versus-Host Disease: II. The 2014 Pathology Working Group Report. Biol Blood Marrow Transplant 21(4):589-603

40. Biedermann BC, Sahner S, Gregor M, Tsakiris DA, Jeanneret C, Pober JS et al (2002) Endothelial injury mediated by cytotoxic $T$ lymphocytes and loss of microvessels in chronic graft versus host disease. Lancet 359(9323):2078-2083

41. Palomo M, Diaz-Ricart M, Carbo C, Rovira M, Fernandez-Aviles F, Martine $\mathrm{C}$ et al (2010) Endothelial dysfunction after hematopoietic stem cell transplantation: role of the conditioning regimen and the type of transplantation. Biol Blood Marrow Transplant 16(7):985993

42. Schmid PM, Bouazzaoui A, Doser K, Schmid K, Hoffmann P, Schroeder JA et al (2014) Endothelial dysfunction and altered mechanical and structural properties of resistance arteries in a murine model of graft-versus-host disease. Biol Blood Marrow Transplant 20(10):1493-1500

43. Pophali PA, Klotz JK, Ito S, Jain NA, Koklanaris E, Le RQ et al (2014) Male survivors of allogeneic hematopoietic stem cell transplantation have a long term persisting risk of cardiovascular events. Exp Hematol 42(2):83-89

44. Rovó A, Tichelli A (ed) (2012) Cardiovascular complications in long-term survivors after allogeneic hematopoietic stem cell transplantation. Seminars in hematology. Elsevier

45. Tichelli A, Bucher C, Rovó A, Stussi G, Stern M, Paulussen M et al (2007) Premature cardiovascular disease after allogeneic hematopoietic stem-cell transplantation. Blood 110(9):3463-3471

46. Nürnberger W, Willers R, Burdach S, Göbel U (1997) Risk factors for capillary leakage syndrome after bone marrow transplantation. Ann Hematol 74(5):221-224

47. Spitzer TR (2001) Engraftment syndrome following hematopoietic stem cell transplantation. Bone Marrow Transplant 27(9):893-898

48. Yabe H, Yabe M, Koike T, Shimizu T, Morimoto T, Kato S (2010) Rapid improvement of life-threatening capillary leak syndrome after stem cell transplantation by bevacizumab. Blood 115(13):27232724 